\title{
La paz territorial como enfoque para comprender la justicia transicional y la construcción de paz en Colombia: mirada desde el Distrito Especial de Santiago de Cali ${ }^{1}$
}

\section{Territorial peace as an approach to understanding transitional justice and peacebuilding in Colombia: view from the Special District of Santiago de Cali}

pp. 98-118

Valentina Betancourt TorRes ${ }^{2}$

REC: $24 / 05 / 2021$

CARlos ANdrés DUQue ACOSTA ${ }^{3}$

\section{Resumen}

La implementación de medidas de justicia transicional en Colombia está condicionada a las posibilidades de paz en los territorios. En ese sentido, este artículo refleja resultados de un proyecto de investigación que tuvo dentro de sus objetivos aportar a la comprensión del enfoque de paz territorial - analizando sus posibles elementos teóricos constitutivos-, así como identificar las miradas que sobre dicho enfoque tienen algunos actores sociales, políticos y administrativos participantes en el proceso de elaboración, aprobación y adopción del Plan de Desarrollo de Santiago de Cali 2020-2023.

Palabras clave: justicia transicional, paz territorial, plan de desarrollo local, Santiago de Cali.

1. El artículo de revisión que aquí se presenta es producto de investigación del proyecto "Plan de Desarrollo de Santiago de Cali 2020 2023: ¿hacia una propuesta con enfoque de paz territorial?", realizado en el marco de la VI Convocatoria Interna de Proyectos de Investigación de UNICATÓLICA, Cali.

2. Abogada, Universidad de San Buenaventura Cali. Magíster en Derechos Humanos y Democratización, Universidad Externado de Colombia. Jefe del Departamento de Ciencias Jurídicas y Políticas de Unicatólica. Vinculada al Grupo de Investigación en Derecho y Ciencias Políticas de Unicatólica. Correo electrónico: vbetancourt@unicatolica.edu.co - Orcid: https:// orcid.org/ 0000-0002-6004-3980.

3. Doctor en Filosofía por la Universidad Estadual de Campinas (Unicamp), Brasil. Matemático, profesional en filosofía y magíster en Filosofía por la Universidad del Valle. Mención de honor en los Premios Nacionales en Ciencias y Solidaridad, Alejandro Ángel Escobar, 2020. Realizó en 2016 un semestre de pasantía de investigación en la Universidad de Westminster, Londres, Inglaterra, bajo la dirección de la politóloga internacional Chantal Mouffe. Investigador-becario de Colciencias entre 2015 y 2019 . Actualmente profesor de Unicatólica, Cali. Correo electrónico: caduque@unicatolica.edu.co - Orcid: https:// orcid.org/ 0000-0002-1171-4805. 


\section{Abstract}

The implementation of transitional justice measures in Colombia is conditional on the possibilities of peace in the territories. In this sense, this article reflects the results of a research project that had within its objectives to contribute to the understanding of the territorial peace approach - analyzing its possible constitutive theoretical elements-, as well as identifying the views that about this approach have some social, political and administrative participant actors in the process of preparation, approval and adoption of the Santiago de Cali Development Plan 20202023.

Keywords: transitional justice, territorial peace, local development plan, Santiago de Cali.

\section{Introducción}

Hacia el año 2014, el entonces alto comisionado para la paz en Colombia, Sergio Jaramillo, expresó que el acuerdo de paz adelantado con la guerrilla de las FARC tenía como propósito poner fin al conflicto para construir paz con enfoque territorial, esto es, priorizando la defensa de los derechos fundamentales y el fortalecimiento de las instituciones del Estado para atender las necesidades particulares de los territorios y permitir que su población se movilice alrededor de la paz (Jaramillo, 2014, pp. 1-2).

En ese sentido, se proponía que la construcción de paz en el país solo sería posible a través de procesos de planeación participativa de "abajo hacia arriba" en los territorios. Dicho proceso suponía el trabajo articulado entre las comunidades y las "autoridades" locales, quienes conjuntamente identifican las necesidades de su entorno y dan respuesta a las mismas a través de un trabajo concertado y metódico, haciendo que la gente sienta como propio su proceso de reconstrucción (Jaramillo, 2014, p. 4).

En ese esfuerzo y tarea conjunta son bienvenidos distintos actores: grupos de víctimas, empresarios, estudiantes, grupos étnicos, organizaciones no gubernamentales, funcionarios e instituciones públicas, etc. Según esta lógica, la construcción de paz y la implementación efectiva de las medidas de justicia transicional no se logran ni interviniendo los territorios con una mirada centralista, ni las comunidades por sí mismas sin articulación con las fuerzas estatales. Insistir en esa lógica sería hacerle el juego a la fragmentación y relación de tensión que tanto daño ha hecho en la sociedad, exacerbando las ausencias estatales en los sectores y poblaciones más vulnerables.

En palabras de Jaramillo (2014):

Lo que necesitamos es imponer una lógica de inclusión e integración territorial, basada en una nueva alianza entre el Estado y las comunidades para construir conjuntamente institucionalidad en el territorio. "Institucionalidad" entendida nuevamente no sólo como la presencia de unas entidades estatales, sino como el establecimiento conjunto de unas prácticas y normas que regulen la vida pública y produzcan bienestar. (p. 5)

Este llamado a la construcción de paz territorial implica la asunción de responsabilidades y tareas por parte de gobernadores y alcaldes; en otras palabras, se hace necesario evaluar la participación de los entes territoriales en dicho proceso de construcción colectiva. Esteesfuerzo implica también reivindicar el trabajo por la legitimidad de las instituciones, 
tan afectada durante años de conflicto y las muchas veces infructuosa puesta en marcha de programas y proyectos para ponerle fin y reivindicar los derechos de las víctimas.

Una de las formas de implementar las medidas de justicia transicional con enfoque de paz territorial es a través del proceso participativo de elaboración y aprobación de los planes de desarrollo regionales y locales. Este proceso implica que distintos actores (sociales, políticos, administrativos), decidan incluir la construcción de paz como eje central de sus apuestas a futuro. Esto es importante si tenemos en cuenta que la construcción de paz territorial se corresponde con el fortalecimiento del Estado local; este, a su vez, se ha evaluadao a través de índices de desempeño integral en los que el avance en el cumplimiento de las metas establecidas en los Planes de Desarrollo Local cobra especial importancia (García et al., 2016, p. 30).

Así las cosas, en este documento se pretende dar cuenta de dos cuestiones, a saber: (i) aportar a la comprensión del enfoque de paz territorial en tanto visión integradora y transformadora de la justicia transicional, e (ii) identificar las miradas que sobre la justicia transicional y la paz territorial tienen algunos actores participantes en el proceso de elaboración y aprobación del Plan de Desarrollo de Santiago de Cali 2020-2023. Por último, a manera de recapitulación se destacan algunas conclusiones que abran camino para la implementación de medidas de justicia transicional y, ¿por qué no?, políticas públicas locales a partir del enfoque de paz territorial objeto de comprensión y estudio.

\section{M etodología}

La investigación que da origen a los resultados o propuesta que aquí se presentan, se ubica dentro del paradigma constructivista, al reconocer la naturaleza múltiple, diversa y subjetiva de la realidad social de cara a la comprensión del enfoque de paz territorial a partir de la variedad de miradas y perspectivas de actores políticos, sociales y administrativos de Santiago de Cali.

Así las cosas, estamos ante una investigación de tipo cualitativo que desarrolla sus objetivos de investigación a través de dos estrategias metodológicas: la estrategia documental, mediante la cual se realiza una exploración bibliográfica del enfoque de paz territorial, destacando algunos rasgos característicos del concepto que pueden facilitar su comprensión, y la realización de entrevistas mixtas o semiestructuradas a diecisiete participantes, entre los cuales se cuentan tres miembros de la administración municipal de Santiago de Cali, ocho concejales del distrito y seis miembros del Consejo Territorial de Planeación.

El método de interpretación de las entrevistas y el rastreo bibliográfico se inscribe dentro de la propuesta de la teoría fundamentada, al implicar recolección y análisis simultáneo de datos de manera flexible, abordando el objeto de estudio con el fin de generar una teoría acerca del mismo (Bonilla y López, 2016, p. 307). Dicho método consiste entonces en la recolección, codificación y análisis de datos de manera que el muestreo teórico descubra las características o atributos de la categoría (Bonilla y López, 2016). Para el caso que nos ocupa, se trató de analizar los fundamentos teóricos del enfoque de paz territorial a través de unas características que se destacan en la revisión analítica de este documento, al tiempo que se indagaron las miradas, concepciones y conocimientos de los actores entrevistados alrededor de dichas categorías de análisis. 


\section{Revisión analítica}

\section{¿Qué es paz territorial?}

\section{Un intento de definición}

Lo primero que hay que tener en cuenta en la apuesta de fundamentación de la paz territorial es que la propuesta de Jaramillo (2014) puso de presente la necesidad de pensar la implementación de los acuerdos de La Habana desde un enfoque que trasciende el predominio institucional. Es decir, la construcción de paz no se logra imponiendo un conjunto de medidas o políticas nacionales de arriba hacia abajo, sino contando con las necesidades y expectativas de los territorios en los que dichas medidas serán puestas en marcha.

De esta manera, podríamos decir que dentro de las múltiples miradas y concepciones de paz, el enfoque de paz territorial adopta las siguientes características: 1) Emerge desde la concepción de paz positiva; 2) Se sustenta en la visión de construcción de paz desde el territorio; 3) No es posible sin participación ciudadana activa; y 4) Implica el fortalecimiento de los Estados locales.

\section{El reconocimiento de la paz positiva}

En un trabajo sobre los retos de la paz territorial, Vargas y Hurtado (2017, p. 8) mencionan que la implementación de los acuerdos de La Habana compromete de manera directa las competencias de las entidades territoriales. De esta manera, los autores identifican al menos doce sectores que requieren atención y esfuerzos integrales para trabajar hacia la paz territorial, de acuerdo con variables como los niveles de pobreza, el grado de afectación derivada del conflicto, la debilidad institucional administrativa y la presencia de cultivos ilícitos. Estos sectores son: vías, riego, energía, educación, salud, nutrición, vivienda, agua potable, economía campesina, catastro, drogas, seguridad y justicia transicional. Nótese que en muchos de estos casos nos estamos refieriendo a la garantía de derechos humanos fundamentales, considerados como bienes básicos para la vida digna; entre ellos se puede contar la necesidad de que la población en los territorios cuente con servicios básicos de salud, vivienda y educación, entre otros.

No en vano la mayoría de municipios priorizados para el posconflicto (34 de 50), que hoy por hoy cuentan con planes de desarrollo territorial (PDET), se encuentran en zonas rurales que requieren altos esfuerzos integrales de superación de brechas y carencias en cuanto a la garantía de los servicios y condiciones arriba mencionados.

Los retos de la paz territorial en los términos anteriormente expuestos nos llevan a pensar que este enfoque se fundamenta a partir del concepto de paz positiva. Este propone una visión holista de la paz que se caracteriza por la ausencia de violencia tanto directa como estructural o indirecta (Harto de Vera, 2016, p. 129).

Lo anterior quiere decir que la paz no se alcanza únicamente con la ausencia de conflicto y confrontación armada (visión de paz negativa), sino garantizando la justicia social que implica la concreción de los derechos humanos, es decir, libertades individuales y colectivas, derechos sociales, económicos y culturales, e incluso derechos colectivos y del medio ambiente. Esto último resulta especialmente importante, teniendo en cuenta que autoras como Lederach, por ejemplo, vienen proponiendo una conceptualización mucho más amplia de la paz a partir de un análisis antropológico multiespecies. Su trabajo parte de un análisis etnográfico en comunidades 
de los Montes de María, a través del cual se logra comprender las relaciones entre los grupos humanos y las lógicas ambientales y ecológicas que se viven en el territorio. En palabras de la autora: "insisto en que el análisis académico de paz territorial requiere un enfoque que preste especial atención a las maneras en que los campesinos construyen paz dentro de una ecología de múltiples relaciones de cuidado" (Lederach, 2019, p. 176).

Así las cosas, si la paz positiva debe identificarse principalmente con la justicia social, a la que se ha definido como distribución igualitaria de recursos y participación igualitaria en la toma de decisiones sobre esta distribución (Trifu, 2018, p. 34), esto explicaría por qué el enfoque de paz territorial transversal a todo el acuerdo de paz firmado en La Habana tiene por objetivo la consecución de una paz estable y duradera. Tal como afirma Trifu, a partir de sus indagaciones sobre el desarrollo del concepto de paz positiva, esta tendría relación directa con la superación y ataque contra la injusticia social, que es al mismo tiempo la implantación de la violencia estructural. En ese sentido, el estudio de la paz positiva supone la comprensión de las causas de la violencia y las condiciones para la paz, buscando ambas en las estructuras sociales (Trifu, 2018, p. 34). Bien es sabido que las causas estructurales de la violencia en el caso colombiano se encuentran en la desigualdad social y la violencia política. En esa línea, el Centro Nacional de Memoria Histórica (CNM H) (2013) afirmó que:

A pesar del gran dinamismo del conflicto armado, hay aspectos recurrentes. Estos configuran las continuidades de la guerra y aparecen de manera reiterada en los diagnósticos que la explican. Entre otros, se cuentan la concentración de la tierra que impide resolver el problema agrario; la presencia desigual del Estado en las periferias del país, aunado a una integración territorial precaria y un creciente abandono del país rural; la prevalencia de una economía extractiva que no solo desconoce los derechos de sus legítimos e históricos propietarios, sino que depreda, arrasa y acumula sin generarun desarrollo social sostenible. (p. 192)

Por la misma línea, se manifestó que:

Históricamente han sido escasas las respuestas del Estado que apuntan a establecer reformas políticas y medidas económicas que transformen la fuente de los problemas, muchos de ellos relacionados con la corrupción, pero especialmente con la vergonzosa inequidad que hace de este país como uno de los más desiguales del mundo. (CNMH, 2013, p. 23)

De esta manera, pensar en la implentación de acciones diferenciadas desde los territorios, ampliando las oportunidades de participación de la ciudadanía, las asociaciones de víctimas y comunidades en general, ampliaría las posibilidades de conocer y atender demandas históricas relacionadas con el trabajo de la tierra, la situación particular en zonas rurales, y las situaciones de exclusión, discriminación y desigualdad potenciadas históricamente a través del conflicto armado.

\section{La importancia del enfoque territorial}

El acuerdo final de paz estableció que el enfoque territorial supone:

\footnotetext{
Reconocer y tener en cuenta las necesidades, características y particularidades económicas, culturales y sociales de los territorios y las comunidades, garantizando la sostenibilidad socio-ambiental; y procurar implementar las diferentes medidas de manera integral y coordinada, con la participación activa de la ciudadanía. La implementación se hará desde las regiones y territorios y con la participación de las autoridades territoriales y los diferentes sectores de la sociedad. (Gobierno y FARC-EP, 2016, p. 6).
} 
En ese sentido, dicho instrumento para poner fin al conflicto armado incluyó la creación de los denominados Programas de DesarroIlo con Enfoque Territorial (PDET), los cuales fueron reconocidos como instrumentos de reconciliación en el que todos los actores trabajan en la construcción del bien supremo de la paz, derecho y deber de obligatorio cumplimiento (Decreto 893 de 2017).

Estos programas suponían la consecución de dos cuestiones, a saber: 1) la realización del principio de participación de las comunidades en la planeación, ejecución y seguimiento de planes territoriales; y 2) la transformación de condiciones sociales, económicas, políticas y culturales de los territorios, para la superación de condiciones que han prolongado el conflicto armado garantizando su no repetición (Decreto 893 de 2017).

Cabe resaltar que la realización de estos planes prioriza las zonas rurales del país en donde el conflicto armado ha azotado con mucha más fuerza. Así las cosas, la finalidad de estos programas coincide con el acuerdo sobre reforma rural integral suscrito en La Habana, tendiente a la transformación estructural del campo, a una relación equitativa entre el campo y la ciudad, y al desarrollo de la economía campesina y familiar (Corte Constitucional, Sentencia C-730 de 2017).

Para la implementación de los PDET se priorizaron 16 zonas en 170 municipios donde estos tendrán cobertura geográfica. Dicha priorización tuvo en cuenta cuatro factores: 1) el grado de afectación derivado del conflicto; 2) la presencia de cultivos de uso ilícito u otras economías ilegales; 3) los índices de pobreza multidimensional; y 4) la debilidad de la institucionalidad administrativa y de la capacidad de gestión de las administraciones locales.
Así, dichos planes contribuirían a la realización de procesos participativos con enfoque territorial al tener en cuenta

las características sociohistóricas, culturales, ambientales y productivas de los territorios y sus habitantes, sus necesidades diferenciadas y la vocación de los suelos, de conformidad con las normas orgánicas de planeación y ordenamiento territorial. (Decreto 893 de 2017)

Es claro entonces que estos programas se construyen a partir de un enfoque participativo y territorial que tiene en cuenta sobre todo la visión del territorio de las comunidades, grupos y organizaciones que lo habitan y desean transformar condiciones de pobreza, exclusión y victimización.

La existencia y desarrollo de los PDET fue avalada por la Corte Constitucional:

IOS PDET's contribuyen a la realización del componente social del Estado Social de Derecho, a la realización de derechos fundamentales, económicos, sociales y culturales; a la garantía del derecho a la igualdad entre comunidades urbanas y rurales; a la garantía del derecho a la igualdad entre comunidades étnicas y mestizas, así como al derecho al ambiente sano y, a la vez, permiten la materialización del derecho a la paz y el cumplimiento de buena fe del Acuerdo Final. (Corte Constitucional, Sentencia C-730 de 2017)

El Sistema Integral de Verdad, Justicia, Reparación y No Repetición, incluido igualmente en el acuerdo de paz, también implica la sujeción al enfoque territorial. Así, en el Decreto 588 de 2017, a través del cual se organiza la Comisión para el Esclarecimiento de la Verdad, se expresa que:

ARTÍCULO 70. Enfoque territorial. La CEV será una entidad de nivel nacional pero tendrá un enfoque territorial con el fin de lograr una 
mejor comprensión de las dinámicas regionales del conflicto y de la diversidad y particularidades de los territorios afectados, y con el fin de promover el proceso de construcción de verdad y contribuir a las garantías de no repetición en los diferentes territorios. El enfoque territorial tendrá en cuenta también a las personas y poblaciones que fueron desplazadas forzosamente de sus territorios.

La CEV podrá crear grupos de trabajo en el territorio nacional de acuerdo a lo establecido en su reglamento.

Si bien dicho enfoque territorial implicó la regionalización del trabajo de la Comisión, creando oficinas descentralizadas, lo cierto es que la transición hacia la paz y la democratización del territorio requiere el trabajo focalizado en todas las regiones. En un informe de recomendaciones a esta organización, la Comisión Colombiana de Juristas (CC) (2018) mencionó que

la CEV debe ir mucho más allá y no podrá depender de otras instituciones que, como se ha visto en la práctica, no tienen la capacidad real - la voluntad política de descentralizarse 0 contribuir a la verdad y no tienen una presencia efectiva en muchos de los territorios más afectados por el conflicto armado. Como ya se mencionó, tampoco hay que perder de vista el trabajo territorial en las regiones que han sido epicentro de la violencia y el conflicto armado, pero no quedaron incorporadas dentro de esta priorización territorial, por ejemplo, grandes ciudades como Medellín y Cali. (p. 20)

Otra cuestión interesante sobre el trabajo con enfoque territorial es que el manejo de categorías geográficas no puede ser simplemente el tradicional, con las unidades político-administrativas como departamentos y municipios, porque estas no permiten una comprensión detallada de las dinámicas regionales del conflicto armado (CC), 2018, p. 21).
Es conveniente avanzar hacia análisis que permitan el entendimiento de los territorios en sus particularidades y sus correlaciones geográficas entendiendo la multidimensionalidad del espacio; donde las categorías, así como los imaginarios, puedan ser plasmados de forma sistemática (CC), 2018, p. 21).

Además de lo anterior, no se debe olvidar que la necesidad de implementar dicho enfoque para la adopción de medidas de reparación a víctimas ya había sido contemplado en uno de los hitos jurídicos más importantes en la configuración del modelo de justicia transicional, a saber, la Ley 1448 de 2011.

En dicho instrumento jurídico expedido durante el primer gobierno Santos, se establecen en cabeza de las entidades territoriales diferentes obligaciones de asistencia y garantía en la aplicación de medidas de reparación a favor de las víctimas del conflicto sujetas a su jurisdicción. Esto quiere decir que las medidas adoptadas a favor de este grupo poblacional debían acercarse a los territorios favoreciendo las posibilidades de acceso, y teniendo en cuenta las condiciones particulares y diferenciadas de los mismos.

En cuanto a la reparación colectiva, se establece que:

Art. 152. SUJETOS DE REPARACIÓN COLECTIVA. Para efectos de la presente ley, serán sujetos de la reparación colectiva de que trata el artículo anterior:

1. Grupos y organizaciones sociales y políticos;

2. Comunidades determinadas a partir de un reconocimiento jurídico, político o social que se haga del colectivo, 0 en razón de la cultura, la zona o el territorio en el que habitan, o un propósito común. (Ley 1448 de 2011, negrilla fuera de texto) 
Vale destacar que a través de este instrumento se crean también los Comités Territoriales de Justicia Transicional y las mesas territoriales de víctimas del conflicto, de manera que sus peticiones, perspectivas y necesidades fueran escuchadas y tenidas en cuenta en las diversas instancias de planeación y toma de decisiones. Así, en el artículo 173 de la ley se menciona que los comités territoriales desarrollarán planes de acción en materia de inclusión e inversión social a favor de la población víctima en el marco de sus planes de desarrollo (Ley 1448 de 2011). Dichos instrumentos debían contar asignaciones presupuestales para la impementación de las medidas de atención, restitución, indemnización, rehabilitación y garantías de no repetición a favor de la población víctima del conflicto.

La necesidad de la participación ciudadana activa

El acuerdo final de paz afirma que la participación ciudadana es el fundamento de todo lo acordado en La Habana (Gobierno y FARC-EP, 2016, p. 6). De esta manera, la participación de la sociedad en la construcción de paz incluye la planeación, ejecución y seguimiento de los planes y programas en los territorios, siendo además una garantía para la transparencia (Gobierno y FARC-EP, 2016). Después de décadas de conflicto, Colombia requiere la posibilidad del diálogo entre diferentes sectores de la sociedad. Ello implica la superación de barreras, y la promoción de espacios para el reconocimiento de las víctimas y de lo ocurrido en tantas décadas de confrontación armada.

Exaltar la importancia de la participación ciudadana se corresponde con el enfoque de justicia transicional desde abajo. Esta apuesta se concentra, por una parte, en la participación de actores no estatales en el diseño político y la aplicación de mecanismos de justicia transicional y, por la otra, en prácticas no formales de resolución de conflictos en espacios locales (Gómez, 2014, p. 18).

De esta manera, para la implementación y arraigo de las medidas de justicia transicional se deben reconocer las realidades y experiencias de las sociedades no occidentales que han padecido graves y masivas violaciones a los derechos humanos. Ya afirmaban Saffón y Tacha $(2018$, p. 29) que la promoción, adopción e implementación de las medidas de justicia transicional vigentes en Colombia, han contado con la participación de las víctimas y algunas organizaciones sociales, cuyo empoderamiento e incidencia política ha sido esencialmente una conquista "desde abajo", que ha tenido lugar en los procesos de paz gestados históricamente.

Para que el derecho a la participación verdaderamente garantice la democracia participativa y el reconocimiento de la pluralidad, se debe garantizar que todas las personas y poblaciones que ocupen la zona donde se llevan a cabo los procesos de planeación participen en condiciones de equidad, incluso a través de la adopción de acciones afirmativas favorables a poblaciones especialmente discriminadas (Corte Constitucional, Sentencia C-730 de 2017) (Figura 1).

\section{¿El enfoque de paz territorial en el Distrito de Santiago de Cali?}

Uno de los principales aportes de este documento como producto de investigación se deriva de la recolección de información a través de entrevistas semiestructuradas a actores políticos, administrativos y sociales que participaron en el proceso de diseño y elaboración del Plan de Desarrollo de Santiago de Cali 2020-2023. 
Figura 1

Elementos para comprender la paz territorial.

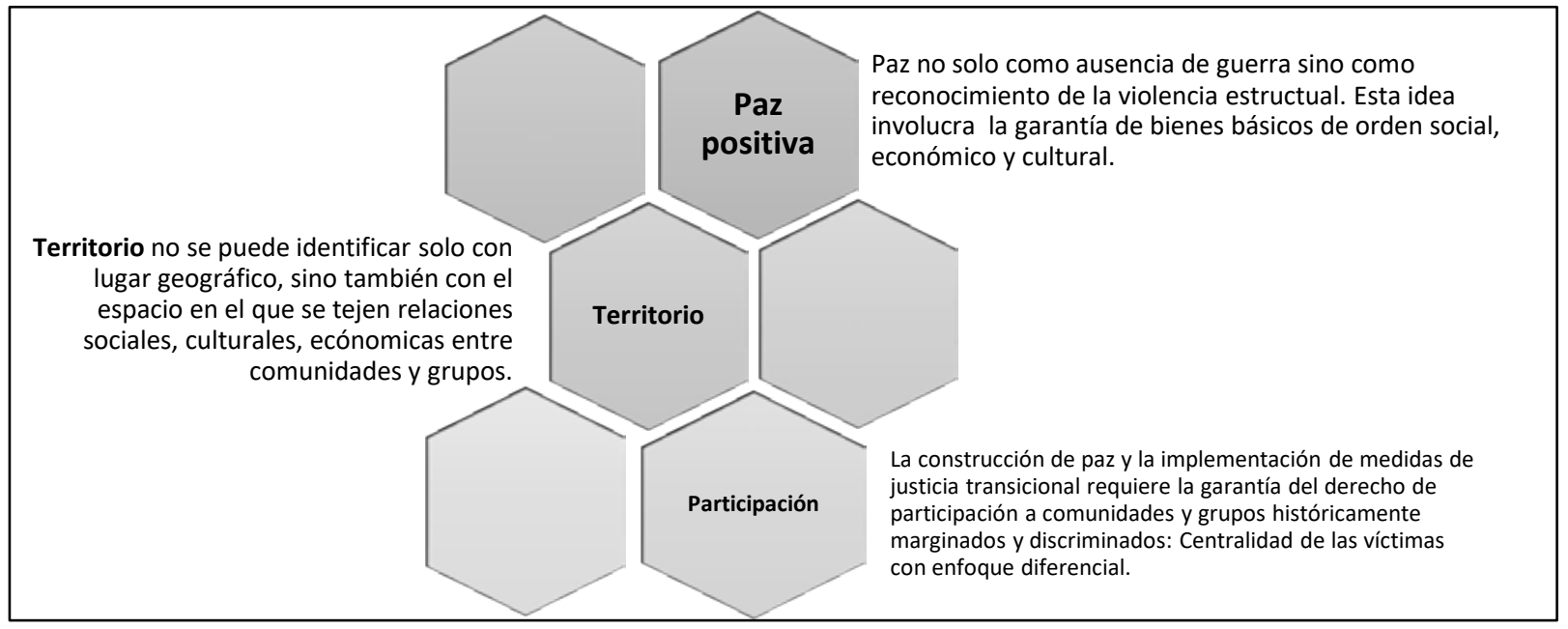

Fuente: Elaboración propia.

La ley nacional distingue entre autoridades e instancias de planeación. Para el caso de los municipios, son autoridades de planeación: el alcalde, el Consejo de Gobierno Municipal, la secretaría de planeación y las demás secretarías especializadas en su ámbito funcional. Mientras que las instancias de planeación son: el Concejo Municipal y el Consejo Territorial de Planeación Municipal (Ley 152 de 1994).

Estas autoridades e instancias participan de diferentes maneras en el proceso de elaboración y aprobación del plan de desarrollo territorial. Así, el proceso inicia con la elaboración del proyecto del plan a cargo del alcalde y las autoridades y organismos de planeación, para su posterior presentación ante el Consejo Territorial y el Concejo Municipal. Será este último el encargado de aprobar el proyecto dentro de los cuatro meses siguientes a la posesión del alcalde (Ley 152 de 1994). Veamos cómo participaron cada uno de estos órganos en el proceso de discusión y aprobación de dicho documento, pero sobre todo, cuáles son las miradas y concepciones de los mismos sobre cuestiones que evidencian o no la comprensión del enfoque de paz territorial.

Particularmente, y para efectos de comprender las miradas de los actores entrevistados sobre el tema de discusión, me enfocaré en las respuestas dadas por los participantes a cuatro interrogantes, a saber: 1) ¿cuál es su visión general del marco instaurado por la justicia transicional en Colombia?; 2) ¿qué entiende usted por paz?; 3) ¿qué entiende usted por territorio?; y 4) ¿para usted, el plan de desarrollo aprobado fue una elaboración colectiva, participativa, ciudadana?

\section{Autoridades administrativas de la ciudad de Cali}

El pasado 27 de octubre de 2019, la ciudadanía caleña eligió a Jorge Iván Ospina Gómez como alcalde municipal, contando con el $38 \%$ del total de votos electorales en representación de la Coalición Puro Corazón por Cali (Misión de Observación Electoral, 2019). 
En el programa de gobierno con el que se inscribió como candidato al cargo se percibe una preocupación por la poca comprensión de las realidades y necesidades territoriales tanto en el entorno urbano como en el rural. Así, en dicho documento se menciona que:

Es posible identificar que a pesar de la reciente reforma administrativa 0536 del año 2016 se mantienen problemas de sistematicidad y aplicación de procedimientos institucionales, por su alejamiento de la realidad territorial, y se observa una distancia entre los planes operacionales de las agencias del municipio y las necesidades y demandas ciudadanas, especialmente en la provisión de servicios y en la generación de oportunidades para el bienestar colectivo. (Coalición Puro Corazón por Cali, 2019, p. 9)

La primera versión de Plan de Desarrollo para el periodo actual fue presentada por el alcalde ante las instancias correspondientes el 28 de febrero de 2020. Esta propuesta titulada "Cali, territorio de reconciliación", auncuando se expresa en términos de la importancia de entender a Cali como "territorio" 4 inteligente, de reconciliación, sustentable y sostenible, no define particularmente qué entender por territorio y cómo se asume dicha comprensión en la apuesta de desarrollo para la ciudad. Sin embargo, la Dimensión 1 del proyecto de plan, relativa a la idea de territorio sustentable, sí parece incluir la dimensión socioambiental intrínseca a la noción de territorio, así como las formas de habitarlo:

(...) es necesario desarrollar estrategias encaminadas a cuidar de Cali como nuestra Casa Común, entendiendo la sustentabilidad como las capacidades propias para generar un nuevo relacionamiento con el medio, haciéndonos auto sostenibles en el tiempo, en el marco de un nuevo urbanismo y una nueva forma de morar la ruralidad, que implica la renovación y la innovación en nuestras formas de habitar, movilizarnos, producir, planear la vida en común, vivir el espacio público, generar los servicios públicos e integrarnos en el territorio, transformando nuestras relaciones de convivencia social y especialmente con la naturaleza y los otros seres sintientes. (Alcaldía de Santiago de Cali, 2020, p. 25).

Dicha visión, pese a las modificaciones que se incluyeron en el plan de desarrollo aprobado, concibe al territorio como potenciador de todas las dimensiones del nuevo proyecto de ciudad desde sus diversas dimensiones: económica, política, social, ambiental. También se menciona en él, la necesidad de prepararse hacia el diseño e implementación de los Planes de Desarrollo de Comunas y Corregimientos dado el carácter de Santiago de Cali como Distrito Especial (Alcaldía de Santiago de Cali, 2020, p. 21).

Ya en lo relativo a la realización de entrevistas como estrategia de investigación, en el proceso de recolección de información fue posible entrevistar a tres directivos de la Alcaldía de Cali a saber: Secretario de Gobierno, Director del Departamento Administrativo de Planeación Distrital y Secretario de Paz y Cultura Ciudadana. A continuación se realizará un recuento y un análisis de sus respuestas a los interrogantes antes especificados.

A la pregunta sobre cuál es la visión de los participantes sobre el marco de justicia transicional instaurado en Colombia, se tuvieron tres miradas que vale la pena resaltar, así:

1. La justicia transicional se identifica con algunas de las medidas de justicia y reparación que se están implementando 
actualmente, como la Jurisdicción Especial para la Paz y el desarrollo de programas y proyectos para la reparación a las vícitmas del conflicto y los reincorporados en la región. En este punto se mencionaron proyectos locales de vivienda para recepción de desplazados como Potrero Grande y Llano Verde.

2. La justicia transicional se relaciona directamente con los Acuerdos de Paz de La Habana como posibilidad de poner fin a la guerra en el país y buscar la implementación de lo acordado en los territorios locales y regionales.

3. La justicia transicional es "un dispositivo avanzado, ideal, (...), que partió de reconocer experiencias globales en el mundo, (...) pero que funciona más por algunos elementos de corte democrático en las Cortes", sin embargo su camino de implementación es pedregoso y no ha podido funcionar la experiencia.

De las respuestas anteriormente destacadas, podría decirse que existe una comprensión limitada sobre la justicia transicional en la que esta se identifica, o bien con alguna medida de transición (Jurisdicción Especial para la Paz), con un hito que permitió su configuración en el país (el Acuerdo de La Habana), o un enfoque de comprensión de la misma (enfoque idealista que la entiende como un conjunto de medidas jurídicas para la satisfacción de derechos violados). Esa situación evidencia la necesidad de proponer una visión holista e integral de la justicia transicional, a través de la cual las autoridades administrativas puedan pensar en las posibilidades de implementar las medidas de transición en los territorios teniendo en cuenta variables como hechos victimizantes y modalidades de violencia ejercidos en los mismos, población víctima con presencia en nuestra ciudad, y principales desafíos para la reconstrucción del tejido social a partir de los daños ocasionados diferencialmente por el conflicto armado interno.

Sobre las visiones de paz que tienen los participantes, se encontró que:

1. La paz debe entenderse desde una visión más integral "como la posibilidad de desarrollar los proyectos de vida de manera colectiva, de manera concertada, tramitando los conflictos de manera no violenta y fortaleciendo la construcción de tejido social". Esto se logra con el empoderamiento de las comunidades y el fortalecimiento de sus iniciativas comunitarias.

2. La paz puede comprenderse como un concepto polisémico que depende de las experiencias de vida de cada persona.

3. La paz es un conjunto de acciones que llevan al desarrollo social y económico de una sociedad.

4. La paz es la construcción de un orden de convivencia en donde se reconoce el conflicto, se reparan integralmente los daños causados y se construye un proyecto renovado de identidad de país.

En ese sentido, si bien uno de los entrevistados relacionó la paz con la ausencia de conflicto y la reparación de los daños causados en virtud del mismo (visión de paz negativa), vale resaltar que existe una posición generalizada sobre la paz desde "una visión más in- 
tegral" que incluya el desarrollo de proyectos colectivos y la construcción de tejido social. No obstante lo anterior, valdría la pena insistir en una postura mucho más comprometida con la paz positiva como justicia social, que en nuestro caso regional, tenga en cuenta los grupos históricamente marginados y discriminados que habitan en nuestro territorio de maneral diferencial.

A la pregunta sobre qué entendería usted por territorio, se pueden destacar las siguientes ideas:

1. “(...) territorio es el espacio en que las comunidades desarrollan sus proyectos, entendido como su base ecosistémica y territorial, pero entendido también con sus procesos históricos y culturales, y con sus modelos de gobernanza".

2. "el territorio (...) es una construción social y cultural que demanda múltiples relaciones ontológicas". Va más allá de elementos de tipo geofísico, encarnando aspectos como el habitar y el morar el espacio, el ejercicio del poder y el lugar donde se tejen relaciones.

3. El territorio responde a dinámicas sociales y económicas en sectores y grupos sociales particulares.

Como se ve de las respuestas dadas, los miembros de la administración municipal entrevistados entienden el territorio como algo más que un espacio físico donde se ejerce el poder, o la división geoadministrativa del mismo. Resulta entonces importante seguir dando contenido a dichas apreciaciones a partir de una comprensión mucho más profunda de las dinámicas históricas, sociales, culturales, económicas y políticas de la ciudad de Cali y las comunidades que la habitan. Esto podrá determinar estrategias para la implementación de programas y proyectos de acuerdo con las características particulares de los territorios, las comunidades y los grupos, según diversos enfoques diferenciales: étnico, de género, territorial, y por supuesto basado en la centralidad de las víctimas del conflicto armado interno.

Al último interrogante, ¿para usted, el plan de desarrollo aprobado fue una elaboración colectiva, participativa, ciudadana?, los secretarios identificaron la situación de pandemia por COVID-19 como una talanquera para la participación activa de la ciudadanía. Sin embargo, hablaron de los esfuerzos por fomentar la discusión colectiva del plan, en el que se contaron más de 20000 personas participantes a través de diversos canales de comunicación e interacción que incluyeron los medios virtuales.

En ese sentido tenemos que, auncuando la pandemia por COVID-19 minimizó las posibilidades de trabajar con las comunidades en sus territorios y propiciar la participación de las mismas en el proceso de discución del plan de desarrollo local, las respuestas dadas por los participantes no exaltan necesariamente la importancia de la participación ciudadana en este proceso. Cabe recordar que el alcalde electo tiene la potestad de proponer el plan territorial encontrándose legitimado a partir de su elección popular derivada del voto programático.

\section{El Concejo M unicipal de Santiago de Cali}

Fueron ocho los concejales municipales entrevistados para los efectos de este proyecto, representantes de siete partidos y movimientos políticos de las nueve bancadas que 
participan en esta corporación. Esto quiere decir que los miembros entrevistados representan al menos el $78 \%$ de los grupos políticos de dicho órgano.

Se eligieron concejales y concejalas de partidos diversos en sus ideas políticas, a saber: Partido Conservador, Partido Liberal, Partido de la U, Polo Democrático, Alianza Verde, Centro Democrático y Firmes con el Chontico.

Corresponde al Concejo municipal adoptar los planes y programas de desarrollo económico y social y de obras públicas (Constitución Política de Colombia, 1991); en este caso, el Plan de Desarrollo del Distrito Especial de Santiago de Cali. De acuerdo con la ley nacional, el Concejo municipal tiene plazo de un mes contado desde el día que el plan de desarrollo sea sometido a su consideración para aprobarlo a través de acuerdo municipal, lo que para el caso de Santiago de Cali sucedió mediante Acuerdo 0477 de 2020.

Dadas dichas competencias normativas en cabeza de los concejos municipales en el orden territorial, resulta innegable la necesidad de considerar sus posturas y miradas sobre los temas que nos ocupan en esta investigación, teniendo en cuenta su potestad para efectuar directamente previsiones sobre asuntos que conciernen a los intereses de la localidad (Sánchez, 2012, p. 143).

De esta manera, al primer interrogante sobre las visiones de los participantes acerca del marco o modelo de justicia transicional en Colombia, se tuvo que:

1. Dos concejales mencionaron que la justicia transicional es un "mecanismo conveniente" para poder darle trámite no violento y solución al conflicto po- lítico armado en Colombia, en aras de buscar la verdad y la reconciliación.

2. Tres participantes la entienden como la posibilidad de obtener justicia, verdad, reparación y no repetición a través de los acuerdos de La Habana, aun con las concesiones que implica un acuerdo fruto de negociación.

3. Dos participantes la consideran un proceso necesario para alcanzar la paz pero cuyo proceso de consolidación e implementación en los entes territoriales es complejo por el desconocimiento de las normas y la falta de voluntad política.

4. Solo una concejala la entiende como un marco legal, usado como vehículo para desarrollar intereses políticos, como el caso del paramilitarismo.

Como se puede ver de las respuestas dadas, todos los participantes coinciden en que a través de la justicia transicional se avanza hacia la consecución de la paz. Sin embargo, su entendimiento sigue siendo precario. Solo el $37 \%$ de los concejales mencionó que está relacionada con medidas de justicia, verdad, reparación y no repetición. La misma cantidad de partipantes relaciona la justicia transicional con los acuerdos de La Habana, pero no con los demás hitos que antecedieron la configuración del modelo con que contamos hoy: el proceso de desmovilización de paramilitares y la expedición de la Ley 1448 de 2011 (o ley de víctimas) con la que se desarrolla específicamente el proceso de reparación integral a las víctimas. Por último, cabe resaltar que solo dos participantes mencionaron que la paz a través de la justicia transicional implica la consolidación e implementación efectiva de dichas medidas en los territorios, 
cuestión que resulta particularmente importante si tenemos en cuenta que es a través de la implementación de medidas con enfoque territorial que se logra superar las graves y masivas violaciones a los derechos humanos de la población víctima, dependiendo de los hechos victimizantes y las condiciones territoriales que propiciaron dichas conductas 0 acontecimientos.

Al interrogante sobre qué se puede entender por paz, se tuvo que:

1. Un participante afirma que la paz coincide con la superación de violencias estructurales y la marginación social de que son víctimas ciertos colectivos y grupos.

2. Un participante la relaciona con la garantía de libertades, seguridad y bienestar de la comunidad.

3. Un participante la relaciona con la posibilidad de vivir tranquilos, y sin guerra.

4. Un participante la relaciona con la generación de igualdad de oportunidades para las personas.

5. Un participante la asocia a la justicia social y el perdón.

6. Un participante la entiende como la posibilidad de gestionar los conflictos a través del diálogo y el reconocimiento de las diferencias.

7. Un participante la comprende como garantías sociales, políticas y económicas en los territorios.

Solo dos de los concejales, representantes del Partido Verde y del Polo Democrático, mencionaron que la consideración de la paz implica tener en cuenta las relaciones interespecie y el reconcimiento del territorio, respectivamente.

Como se ve de las respuestas dadas por los participantes, cuatro de ellos (50\%) relacionan la paz con los elementos de comprensión de la paz positiva, esencialmente las ideas de justicia social, superación de la violencia estructural, garantías sociales, políticas y económicas, y generación de igualdad de oportunidades en los territorios. Sin embargo, todavía persisten visiones que comprenden la paz desde su significado negativo, es decir, la ausencia de guerras y conflictos, al tiempo que hubo un participante con una visión sumamente liberal del concepto, es decir, la comprensión de la paz como libertad y seguridad.

A la pregunta sobre qué se entiende por territorio, se tuvo que:

1. Tres concejales lo identifican como el lugar donde la gente vive, cohabita con otros y desarrolla actividades de todo tipo.

2. Dos concejales lo entienden como el espacio geográfico donde nos encontramos, pero también donde se han padecido las violencias y hechos delictivos de manera diferenciada.

3. Un concejal lo entiende como un barrio, una comuna, una ciudad, desde donde se deben identificar problemáticas puntuales para buscar soluciones efectivas a las mismas.

4. Un concejal menciona que "territorios también tiene que ver con el arraigo social", entonces en el territorio inciden también cuestiones sociales y culturales. 
5. Una concejala menciona que el territorio es un derecho que implica el goce del hábitat y la construcción de un plan de vida a través de el.

En ese sentido, y sobre la comprensión de la noción "territorio", aun cuando hubo participantes que lo relacionan con las divisiones geopolíticas, siempre se agregaron otros elementos para entenderlo, tales como las historias de violencia diferenciada que se han padecido en él, la identificación de problemáticas y necesidades puntuales de las comunidades que lo habitan, el arraigo social y cultural que lo configura y la realización de planes de vida y proyectos a través del mismo.

A la pregunta sobre si el plan de desarrollo de Cali fue una construcción colectiva, participativa y ciudadana:

1. Un concejal considera que hubo participación ciudadana, pero no podría decirse que el plan fue una construcción colectiva en esa dimensión debido a la precariedad de los mecanismos de participación.

2. Un concejal manifiesta que no se logró participación efectiva. Se supone que el plan debió responder a 37 planes: los de 22 comunas y 15 corregimientos que conforman Santiago de Cali.

3. Cinco concejales manifestaron que se cumplieron términos legales y se aumentaron ciertos indicadores, pero esto no quiere decir que la participación ciudadana haya sido efectiva.

4. Un participante mencionó que el Plan de Desarrollo no se construye desde la ciudad. Se construye para ella pero desde la administración municipal.
Como se ve de las respuestas dadas por los participantes, todos coinciden en que la participación ciudadana en el marco de la elaboración y aprobación del Plan de Desarrollo no es efectiva. Dicho déficit se le atribuye a la precariedad de los mecanismos de participación, la falta de un enfoque territorial para gestarla y su consideración como un mero requisito legal. Incluso uno de los participantes negó que la participación ciudadana fuera un requisito sine qua non para aprobar el plan local.

\section{El Consejo Territorial de Planeación de Santiago de Cali}

Los consejos territoriales de planeación (en adelante CTP) son la instancia de planeación a nivel territorial a través de la cual se garantiza la participación ciudadana. Los llamados a participar de este espacio son los sectores económicos, sociales, ecológicos, educativos, comunitarios y culturales (Ley 152 de 1994); sin embargo, las autoridades territoriales podrán determinar la participación de otros que se consideren necesarios para ampliar el margen de representación de autoridades u organizaciones locales. Dicha participación está amparada en la Carta Política colombiana que establece la necesidad de reglamentar los procedimientos para hacer efectiva la participación de la sociedad civil en la discusión de los planes de desarrollo (Constitución Política de Colombia, 1991).

La creación de los CTP coincide con la política de descentralización administrativa originada en los noventa, que a su vez prometía el acercamiento del espacio público local a la ciudadanía.

Para este caso en concreto, fueron seis los consejeros territoriales entrevistados. Además de la presidencia de la corporación, se contó con la participación de representantes 
de diferentes sectores sociales, a saber: educación, medio ambiente, mujeres, personas en situación de discapacidad y sector rural.

A la pregunta sobre cuál es la visión de los participantes sobre el marco instaurado por la justicia transicional en Colombia, los miembros del Consejo Territorial evidenciaron tener posiciones diversas sobre lo que cada uno comprendía sobre justicia transicional. El $50 \%$ de ellos relacionó la justicia transicional con los acuerdos de La Habana y los problemas para su implementación efectiva. Así, sobre la comprensión de la justicia transicional se tuvo lo siguiente:

1. Un consejero la entiende como la necesidad de garantizar justicia y reparación. Justicia vista desde un enfoque retributivo, es decir, la necesidad de que los victimarios respondan por todos los daños provocados en el marco de la guerra.

2. Un consejero la comprende como la importancia de la distribución y propiedad sobre la tierra rural.

3. Una consejera la relaciona con el incumplimiento de los acuerdos de La Habana y la negación de espacios de participación a comunidades y grupos específicos vulnerados.

4. Un consejero la relaciona con la posibilidad de transformarnos culturalmente a través de la gestión de nuestros conflictos y el acercamiento a problemáticas sociales.

5. Una consejera la entiende como la actitud y voluntad política de muchos actores por imponer ciertas medidas de justicia o paz.
6. Una consejera la relaciona con la necesidad de superar la polarización política de los colombianos alrededor de la consecución de la paz.

Dichas respuestas evidencian que los participantes no tienen una noción integral de la justicia transicional. Es decir, no la relacionan con la interdependencia en la aplicación de diversas medidas que pueden permitirle al país atender las graves y masivas violaciones a los derechos humanos cometidas en el marco del conflicto armado interno.

Para el caso colombiano, y ya que los participantes relacionan la justicia transicional con el acuerdo de paz, hubiere sido muy importante que se evidenciara la comprensión del Sistema Integral de Justicia, Verdad, Reparación y No Repetición, pilares y medidas que soportan el modelo de transición adoptado por Colombia en virtud de las negociaciones con las FARC.

Podría decirse que dentro de las visiones de los participantes se incluyen elementos sobre la justicia, la reparación y la no repetición; sin embargo, la comprensión armónica, holista e interelacionada entre estas medidas es clave para comprender el modelo colombiano como una apuesta de paz y justicia desde un enfoque de justicia restaurativa.

A la pregunta sobre qué entiende usted por paz, se tuvo que:

1. Dos consejeros la entienden como la gestión de los conflictos desde el diálogo y el respeto por la diferencia.

2. Dos consejeros la relacionan con la justicia social y la garantía de bienes básicos para la vida digna (salud, educación, vivienda). 
3. Una consejera la entiende como la reconstrucción de proyectos de vida después de la guerra.

4. Una consejera la relaciona como la "restauración" de la sociedad después de los delitos cometidos contra ella.

Como se ve de estas respuestas, tenemos que la mayoría de los participantes (66\%) entiende la paz desde su acepción negativa, es decir, paz como gestión de conflictos, paz como respeto por la diferencia y paz como restauración después de la guerra o conflicto. Solo hubo dos consejeros (33 \%) del órgano encuestado que entienden la paz desde una visión positiva del concepto; es decir, paz como justicia social, y paz como garantía de bienes básicos para la vida digna.

A la pregunta sobre ¿usted qué entiende por territorio?, se pueden destacar los siguientes resultados:

1. Un consejero lo entiende como el espacio geográfico, político y social donde se desarrolla la vida cotidiana.

2. Un consejero expresó que el territorio es "el lugar por donde camina y transita el pensamiento" (haciendo alusión al pensamiento indígena nasa).

3. Una consejera manifestó que entiende por territorio la división geoadministrativa en regiones y ciudades.

4. Una consejera lo comprende como la representación de la unión comunal, barrial, vecinal y familiar desde donde es posible la acción.

5. Una consejera lo define como la propiedad privada y colectiva.
6. Un consejero lo define como el espacio que me rodea, el entorno donde estoy.

Como se desprende de las respuestas dadas, existen diversas concepciones sobre lo que se puede entender por territorio, tres de los consejeros (50\% de los entrevistados), lo relacionan directamente con divisiones de tipo geoadministrativas (ciudad, barrios, comuna, vecindad), agregando elementos de representatividad, acción y desarrollo de la vida cotidiana de comunidades y grupos. Una consejera, desde una visión bastante liberal tal vez, lo asocia con el derecho a la propiedad tanto individual como colectiva; mientras que solo uno de los participantes (17 \% de las personas del órgano entrevistado) lo entiende desde una visión decolonial-indígena como "el lugar donde camina y transita el pensamiento".

A la pregunta, ¿para usted el plan de desarrollo a probado fue una elaboración colectiva, participativa, ciudadana?, cuatro consejeros (66 \% de los miembros del consejo entrevistados), manifestaron que en el proceso de discusión del documento preliminar del Plan de Desarrollo sí se habían podido aportar a los entes administrativos recomendaciones y observaciones de la ciudadanía. Sin embargo, algunos de ellos identifican el Plan de Desarrollo como un documento inconsulto, toda vez que su función se limita a rendir un concepto y formular las recomendaciones que consideren convenientes sin que estas sean vinculantes u obligatorias para las autoridades de la administración municipal.

Con todo, de lo manifestado por los consejeros participantes se tiene una sensación generalizada de que los medios con que cuentan para realizar la labor encomendada son bastante precarios, al tiempo que sus recomendaciones no cuentan con muchas 
oportunidades de ser tenidas en cuenta ni por la administración ni por el Concejo Municipal.

\section{Conclusiones y recomendaciones}

El trabajo presentado en este escrito sugiere que el enfoque de paz territorial puede ser comprendido teóricamente a partir de tres dimensiones o características que refuerzan su fundamentación:

I. Paz positiva, como la consideración de que la paz estable y duradera prometida en los acuerdos de La Habana solo se logra con la superación de la injusticia social y la violencia estructural que han afectado especialmente a la población víctima del conflicto armado interno y a grupos y colectivos históricamente marginados y discriminados (mujeres, jóvenes, grupos étnicos, niños, etc.).

II. El enfoque territorial que sugiere que la construcción de paz y la implementación de las medidas de justicia transicional debe responder a las necesidades y características propias de los territorios y las poblaciones que 10 habitan. Dicho enfoque también supone la resignificación del territorio más allá de su comprensión geoespacial y geoadministrativa.

III. Participación ciudadana activa como posibilidad de garantizar la legitimidad y la efectividad de las medidas de justicia transicional desde las demandas particulares de la sociedad civil y las asociaciones de víctimas.

Además de lo anterior, a través de las entrevistas realizadas se pueden destacar las siguientes conclusiones:
I. La implementación del enfoque de paz territorial requiere de un análisis integral de las diversas miradas de actores que influyen en la configuración de la justicia transicional desde el nivel local. En este caso, se trató de hacer un acercamiento a instancias de autoridades sociales, políticas y administrativas que inciden en el proceso de elaboración y aprobación del plan de desarrollo municipal.

II. En relación con la justicia transicional, las respuestas dadas por los participantes denotan una comprensión poco holista de dicho campo. De ahí que la mayoría de entrevistados relacionen la justicia de transición con ausencia de guerra y los acuerdos logrados en La Habana, pero no halla ninguna referencia a la violación sistemática y generalizada de los derechos humanos que es lo que justamente se intenta atender a nivel de sociedad a través de las medidas de verdad, justicia, reparación y no repetición. En ese sentido, resulta importante seguir gestando espacios de formación sobre la materia, así como de discusión sobre las posibilidades de implementar las medidas y mecanismos de transición a nivel territorial y a partir de enfoques diferenciales que atiendan necesidades localescomunitarias.

III. Las respuestas dadas por los entrevistados evidencian cierta identificación de la paz con la necesidad de superar violencias estructurales; sin embargo, se hace necesario no solo generalizar la comprensión de la paz territorial desde el concepto de paz positiva, sino identificar las violencias e injusticias sociales que afectan de manera 
diferenciada nuestro territorio a nivel local y, particularmente, desde las comunidades víctimas de violación sistemática a sus derechos humanos.

IV. Sobre la noción de territorio, se observa que la mayoría de participantes entrevistados reconocen que en el territorio se tejen todo tipo de relaciones y fenómenos que sobrepasan los límites y referencias geográficas y administrativas. Sin embargo, es claro que la implementación de las medidas de transición con enfoque de paz territorial implican seguir ahondando en las particularidades de comunidades y grupos que habitan la ciudad de manera diferenciada. Dicha necesidad se refuerza si tenemos en cuenta que la ciudad de Cali ha padecido distintas modalidades de violencia como el desplazamiento forzado y el secuestro, al tiempo que alberga mayoritariamente población afrocolombiana, también afectada no solo a raíz del conflicto armado sino históricamente hablando.

V. Por último, ya sobre la posibilidad de participación activa de la ciudadanía en los procesos de planeación con enfoque de paz territorial, preocupa que la mayoría de participantes denuncien la precariedad de los mecanismos de participación que legitimen las políticas públicas locales, y desarrollen efectivamente programas y proyectos de cara a los sentires y demandas de la población.

Así las cosas, se hace necesario seguir insistiendo en procesos de formación política y competencias ciudadanas que faculten a la población no solo a realizar un ejercicio directo de sus derechos políticos, sino a participar a través de mecanismos existentes o que se creen para incidir cada vez más en los procesos de planeación territorial.

\section{Referencias}

Alcaldía de Santiago de Cali (2020). Acuerdo No. 0477 de 2020. Cali Unida por la Vida. Plan de Desarrollo 2020-2023.

Alcaldía de Santiago de Cali (2020). Plan de Desarrollo de Santiago de Cali 2020-2023. Versión preliminar. "Cali, territorio de reconciliación".

Bonilla, M. y López, A. (2016). Ejemplificación del proceso metodológico de la teoría fundamentada. Cinta moebio, 57, 305315. http://dx.doi.org/ 10.4067/S0717$554 \times 2016000300006$

Centro Nacional de Memoria Histórica (CNMH) (2013). iBasta ya! Memorias de guerra y dignidad. Imprenta Nacional. https:// www.centrodememoriahistorica.gov.co/descargas/ informes2013/ bastaYa/ basta-ya-colombia-memorias-de-guerra-y-dignidad-2016. pdf

Coalición Puro Corazón por Cali (2019). Programa de Gobierno 2020-2023 - Siete retos de puro corazón por Cali. https:// www.cali.gov.co/ planeacion/ publicaciones/34626/ programas-gobierno-historicos/

Comisión Colombiana de Juristas (CCJ) (2018). Recomendaciones metodológicas para la Comisión de la Verdad. https:// www.coljuristas. org/ nuestro_quehacer/ item. php?id $=147$

Congreso de la República de Colombia (15 de julio de 1994). Ley 152. Por la cual se establece la ley orgánica del Plan de Desarrollo. Diario oficial 41.450. https://www.funcionpublica.gov.co/eva/gestornormativo/ norma. php?i=327 
Congreso de la República de Colombia (10 de junio de 2011). Ley 1448. Por la cual se dictan medidas de atención, asistencia y reparación integral a las víctimas del conflicto armado interno y se dictan otras disposiciones. Diario oficial 48096.

Constitución Política de Colombia (1991). Gaceta Constitucional n. ${ }^{\circ}$ 116. http://bit.ly/2NA2BRg

Corte Constitucional (12 de diciembre de 2017). Sentencia C-730/17 (Antonio José Lizarazo Ocampo, M. P). https:// www.corteconstitucional.gov.co/relatoria/2017/ C-730-17.htm

García, M., Torres, N., Revelo, J., Espinosa, J. y Duarte, N. (2016). Los territorios de la paz. La construcción del Estado local en Colombia. Dejusticia. https://www.dejusticia.org/wp-content/ uploads/2017/03/ Los-territorios-de-la-paz-la-construcci\%C3\%B3n-del-Estado-local-en-Colombia.pdf

Gobierno de la República de Colombia y FARCEP (2016). Acuerdo final para la terminación del conflicto y la construcción de una paz estable y duradera. http:// www.centrodememoriahistorica.gov.co/ descargas/ finAcuerdoPazAgosto2016/ 12-11-2016-Nuevo-Acuerdo-Final.pdf

Gómez, G. (2014). Justicia transicional en disputa: una perspectiva constructivista sobre las luchas por la verdad, la justicia y la reparación en Colombia, 2002-2012. Editorial Universidad de Antioquia.

Harto de Vera, F. (2016). La construcción del concepto de paz: paz negativa, paz positiva y paz imperfecta. Cuadernos de Estrategia, 183, 119-146. https://dialnet.unirioja.es/ servlet $/$ articulo?codigo $=5832796$
Jaramillo, S. (2014). La paz territorial. Oficina del Alto Comisionado para la Paz. https:// interaktive-demokratie.org/files/downloads/ La-Paz-Territorial.pdf

Lederach, A. (2019). "El campesino nació para el campo": Un enfoque multiespecies hacia la paz territorial en Colombia. Maguaré, 33(2), 171-207. https:// doi.org/10.15446/ mag. v33n2.86200

Misión de Observación Electoral (MOE) (2019). Datos y resultados electorales. Votación alcaldías por partido y municipio. https:// www.datoselectorales.org/datos-y-resultados-electorales/

Presidencia de la República (5 de abril de 2017). Decreto 588 de 2017. Por el cual se organiza la Comisión para el Esclarecimiento de la Verdad, la Convivencia y la no Repetición. http:// es.presidencia.gov.co/normativa/ normativa/ DECRETO $\% 20588 \% 20$ DEL $\% 20$ 05\%20DE\%20ABRIL\%20DE\%202017.pdf

Presidencia de la República (28 de mayo de 2017). Decreto 893. Por el cual se crean los Programas de Desarrollo con Enfoque Territorial. Diario oficial 50247.

Saffón, M. P. y Tacha, V. (2018). La participación en las medidas de justicia transicional. Un estudio comparado. Centro de Estudios de Derecho, Justicia y Sociedad (Dejusticia).

Sánchez, D. C. (2012). Autonomía territorial y potestad normativa-reglamentaria de los Concejos Municipales: Hacia una redefinición del sistema de fuentes del Derecho Administrativo en Colombia. Universidad de Antioquia, Facultad de Derecho y Ciencias Políticas. http:/ / bibliotecadigital.udea.edu. co/ bitstream/ 10495/ 9837/ 1/ SanchezDiana_2013_AutonomiaTerritorialConsejosMunicipales.pdf 
Trifu, L. (2018). Reflexiones sobre la paz positiva. Un diálogo con la paz imperfecta. Revista de paz y conflictos, 11(1), 29-59. https://doi. org/ 10.30827/ revpaz.v11i1.5602

Vargas, G. y Hurtado, R. (2017). Los retos de la "paz territorial". Universidad de los Andes, Centro de Estudios Interdisciplinarios sobre Desarrollo (Cider). https:// cider.uniandes. edu.co/sites/default/ files/ publicaciones/ documentos-de-politica/2017-Documento-politica-retos-paz-territorial.pdf 